\title{
The Challenges Of Implementing High Performance Work Practices In The Nonprofit Sector
}

Alice Robineau, Kedge Business School, France

Marc Ohana, Kedge Business School, France

Sophie Swaton, Université de Lausanne, Switzerland

\begin{abstract}
The last economic crisis raised huge challenges for nonprofit organizations. It is now critical for them to show not only their social legitimacy but also their efficiency and competency to claim for grants (Kearns, Bell, Deem, \& McShane, 2014). For nonprofit organizations, High Performance Work Practices (HPWPs) are a way to foster performance and to answer the challenges that they are currently facing. However, such practices have only been applied to the corporate world to date. The entire philosophy behind nonprofit organizations radically contrasts with the for-profit sector. In particular, the principles and practice of human resource management may be quite different depending on the sectoral context. The aim of this article is precisely to analyze the challenges of implementing HPWPs in nonprofit organizations. In order to explore these challenges, we study the HR practices of a nonprofit organization based in UK which struggles with poverty. The discussion of results highlights good practices that should be applied in the nonprofit sector.
\end{abstract}

Keywords: Nonprofit; Not-For-Profit; Human Resources; High Performance Work Practices

\section{INTRODUCTION}

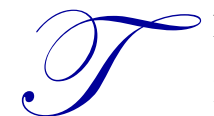

hough it has been considered for a long time as arcane and marginal, the nonprofit sector is now growing and getting more societal and political attention. While no consensus has been reached about which kinds of organizations belong to the nonprofit sector, we define them as bodies which are nonprofit distributing, self-governed, and implementing a charitable or social activity on a voluntary basis, whatever their legal frames. Given the global economic crisis, there is an increase in demand for non-profit oriented activities. Indeed, the crisis creates a need for more social and solidarity organizations. At the same time, the welfare state's activity decreases, due to the global consensus that public deficits should be reduced, which means an increased need for their actions (Ohana \& Meyer, 2010). From a management point of view, it creates a need to develop the organization and its human resources (Ridder \& McCandless, 2010). Besides, as any other industry, the nonprofit sector cannot implement its activities without receiving any income. However, the amount depends on donations from individuals, corporations and governments. In times of crisis, public funding opportunities become scarce and competition between nonprofit organizations (NPOs) for limited funding increases. It is now critical for organizations to show not only their legitimacy to claim for grants, but also their efficiency and competency (Kearns, Bell, Deem, \& McShane, 2014).

The need for a developed and effective staff is a big HR challenge for NPOs. Since the 2000s, the academic literature shows growing interest in High Performance Work Practices (HPWPs) which are seen as a way to foster performance. They aim at matching human resources practices to the organizational environment and strategy. HPWPs capitalize on the workforce, developing it and enhancing commitment through job-related activities. These practices have been proved to be relevant in the business sphere to boost productivity, tackle challenges and increase competitiveness (Sun, Aryee \& Law 2007, Subramony 2009). 
Hence, the problematic of HPWPs seems relevant for the third sector. Indeed, its growth drives it to answer new management challenges and develop novel HR policies and practices. The purpose of this article is precisely to assess to what extent HPWPs might be implemented in NPOs. Indeed, such practices have only been applied to the corporate world to date. Are they relevant for the nonprofit sector? What are the challenges to further their implementation in the nonprofit sector?

We first analyze the human resource practices in NPOs (2); then study the most relevant HPWPs for the nonprofit sector (3); finally report our empirical study resulting from a case study (4) before discussing our results (5).

\section{HPWPS IN THE CONTEXT OF NONPROFIT ORGANIZATIONS}

High Performances Work Practices (HPWPs) are defined as an "integrated system of human resources practices that are internally consistent (alignment among human resources practices) and externally consistent (alignment with organizational strategy)" (Evans \& Davis, 2005). HPWPs are considered as one of the key concepts of the human resource management and organization performance. Organizations that implement such practices are unique in the way that "the division of labor is organized to ensure that all employees are in a position to contribute towards the overall performance of the organization" (Ashton \& Sung, 2002).

Though it remains difficult to gauge the impact of HPWPs, new research indicates that organizations that implement them can raise their productivity by $20 \%-40 \%$. Despite such encouraging figures, estimates suggest that less than $25 \%$ of organizations adopt HPWPs at a sufficient level to drive a real change (Tamkin, 2004). The overall impact of HPWPs on the organization primarily concerns its administrative and financial results. Among others, the effects of HPWPs are highly positive regarding turnover, labor productivity, financial costs, and financial performance.

The implementation of HPWPs may help address the main challenges that NPOs are facing, and could result in a lower turnover rate, a higher efficiency and cost reductions. Nevertheless, HPWPs have mainly been studied in large for-profit companies. The consequences of their introduction into smaller not-for-profit organizations are still pending. There are significant differences between the third sector and the private or public sectors in terms of management (Beck et al., 2008). The convergence across sectors is then irrelevant and might even be inadequate. Some of the characteristics of NPOs are a high commitment to organizational values, the absence of any market mechanism, the importance of values and ethics, as well as a consideration of stakeholders and their expectations (De Cooman et al., 2011; Akingbola, 2006). For instance, the corporate strategy tends to be deeply embedded within its values and missions, making changes harder to manage (Backman et al., 2000).

In this article, we chose to underline what appear to be the five most important practices in the context of NPOs, considering, inter alia, the frequency of mentions in academic papers (Way 2002). We assume that the following five HPWPs are relevant for NPOs: staffing, compensation, training and personal development, flexibility of job assignments, communication. The first three are key human resource management practices, the implementation of which cannot be ignored. The flexibility of job assignments is often reported as enhancing creativity and commitment to the position. Accordingly, it may be another way for organizations to improve their performance and efficiency. Internal corporate communication on strategy holds many advantages. Besides, the specificity of NPOs can be an effective tool for achieving higher outcomes than the for-profit sector.

\section{Staffing}

According to the literature, staffing encompasses the extensiveness of the organization's processes to select, evaluate and hire new employees (Posthuma \& al., forthcoming). The core goal is to select a workforce with superior work skills, which is able to develop them within the organization. Expected results are higher employee output and overall performance (Takeuchi \& al. 2007).

In order to achieve this, the organization has to evaluate knowledge, skills, and determine the right fit for both the position and the organization. The method requires realistic job descriptions, selective screening, and 
assessment of technical and interpersonal skills, attitudes and personality (Way \& Thacker, 2001). Another significant element is the job offer advertisement, which helps get a high-quality applicant pool.

Staffing is particularly relevant for the third sector, which strives to recruit highly educated managers and is subject to high turnover rates. Most research on staffing has highlighted the key role of recruitment for NPOs (Watson and Abzug, 2005). Improving their recruitment practices might tackle both issues. Nevertheless, because of their specificities and constraints, NPOs have to adapt the implementation of this HPWP. Indeed the third sector faces numerous challenges in staffing. The first issue to tackle is the lack of qualified staff interested in the third sector, due particularly to misunderstandings about its essence and actual job opportunities. Moreover, the wellknown phenomenon of uncompetitive salary levels is an obstacle to attracting and retaining qualified applicants. And despite lower wages, the important workload, an integrant part of this sector, is also repulsive for potential candidates (Hurrel et al., 2011). Finally, because of the crisis, funds for NPOs are now often granted as part as a defined project, and contracts are frequently provided on a temporary basis. Consequently, NPOs encounter greater difficulties in attracting qualified candidates (Akingbola, 2006).

\section{Compensation}

Compensation includes both the salary level and the way in which pay is managed. A high wage is more likely to attract, retain and motivate individuals in the workplace (Becker \& Huselid, 1998). Besides, group-based performance pay programs are often mentioned in the literature on HPWPs as a key attractive compensation tool. Compensation is understood as "a way in which firms can align the desires and goals of the employees with those of the firm" (Way, 2002). This system enables teams to work in a collaborative way, towards the same goals, for the organization, the group, and each individual member.

Such pay-oriented systems positively affect turnover and entice employees to provide their skills and positive behaviors to their work-related activities. Compensation levels also play an important role. Not only does a high compensation level attract and increase the importance of the applicant pool, but it also motivates people to apply their skills and knowledge in their working environment, and thus to maintain their level of remuneration. It is also a factor of staff retention since employees tend to stay in their current position when they have a well-paid job. Compensation thus ensures a highly skilled applicant pool, fosters staff involvement, and helps reduce turnover rates.

Among the nonprofit sector, compensation has been a longstanding topic of interest. Research highlights that wages are significantly lower than in the for-profit sphere. The lower pay is described as an "altruism pay off": employees accept reduced salary levels because they share the same values as their organization and deliver a service that makes sense to them (De Cooman et al., 2011; Parry et al., 2005). Compensation in NPOs is influenced by both this altruism pay off and the need to reflect one's non-monetary goals to other stakeholders (Brandl \& Güttel, 2007). Lower wages are a way for NPOs to select an intrinsically motivated and engaged workforce (Handy \& Katz, 1998). Nevertheless, research stresses the importance of the fringe benefits within the organizations, like for instance: flexible working arrangements, career mobility, health insurance, work-family policies, and childcare. The aim is both to attract and retain employees, and compensate, to some extent, the lower pay offered (Haley-Lock \& Kruzich, 2008). However, in the nonprofit sector, fringe benefits are quite low (Ben-Ner et al., 2011).

\section{Training And Personal Development}

The purpose of training employees is to develop and/or teach them new technical skills. Personal Development focuses on the personal soft skills and wishes for one's progression within the organization, which can be both work and personal-related.

Human resource policies usually encompass these two practices. Generally, the bigger the company, the bigger the budget granted. It is not only an investment in finance, but also in time, -since employees undergoing training are not meeting their usual productivity goals. If they quit, then the investment is nil. 
The literature suggests that training and personal development prove to be an efficient way of fostering employees' commitment and of controlling turnover rates (Bartel, 2000). They also have a positive impact on employees' skills and self-esteem, and consequently, on their output (Blanchard \& Thacker 1999).

Training may be a very effective tool in managing employees of NPOs. Nevertheless, research has revealed that resources allocated to training remain scarce (Dolan, 2002). For instance, in the care sector, most of organizations fail to provide their employees with relevant training (De Prins \& Henderickx, 2007). One reason is that NPOs cannot invest as much as big corporations can, in particular owing to their relative small size.

\section{Flexibility Of Job Assignments}

Job rotation and flexibility have two main characteristics: they help develop a high number of skills and increase employee productivity (Wright \& Snell 1998). A job rotation among teams or new job within the organization can be implemented for that purpose. Another way to enhance a job position consists of including new tasks.

Flexibility of job assignments helps expand employee skills, knowledge and ability, as well as one's understanding of the organization. Thanks to new perspectives offered, employees tend to develop novel ideas and to show more interest in applying their skills to their job-related activities (Berg 1999). This may result in a positive impact on the efficiency and development of the organization.

NPOs often adopt creative approaches and have to maintain their dynamism. As they usually are mediumsized, flexibility is a necessity for them. Within a same team, employees frequently share different tasks with their colleagues. Nevertheless, due to heavy workloads and tight deadlines, flexibility through teams is hard to implement. Such organizations have to meet deadlines and produce high quality reports in order to maintain their funding. Indeed, implementing a high degree of flexibility, especially among teams, requires time which not all NPOs have. As a consequence, this specific HPWP can generally not be implemented to the same extent as in the for-profit sector.

\section{Communication}

According to Posthuma et al. (forthcoming), the communication category includes practices dealing with methods whereby information relating to organization performance is exchanged. Communication is important for employees in that it facilitates the expression of their opinions and views in the debate (Way 2002). Having a voice in the organization's strategy and decision process increases the employee's feeling of being part of it. It also shows that the organization cares about its workforce, thus recognizing employee skills. In this way, these are more likely to apply their skills to their job-related tasks.

Another contribution of communication consists in building social bridges within the organization. As nonformal communication increases, faster paths are being created for the information to go through. This helps reduce formal communication, which is time-consuming, thus enhancing efficiency. Besides, a widespread knowledge is created on the role of each department, which allows a better understanding of the whole organization and its functioning.

This HPWP can be completely transferred to the nonprofit sector. It should be a priority, as employees feel very concerned with the organization's purposes and strategy (Ohana et al., 2013). Hence, communication might be much more effective in NPOs than in the corporate world. Not only may it foster the feeling of fairness within the organization, but also help employees keep in mind the rationale behind their contribution to the nonprofit sector. 


\section{EMPIRICAL STUDY}

\section{Methodology}

Our research is based on an explorative, qualitative case study design (Yin, 1993). The case study methodology is particularly suited to exploring complex phenomena embedded in specific contexts. Here, the phenomenon under study is the implementation of HPWPs, and the contextual background is the nonprofit sector. Looking into this complex issue requires the use of multiple sources of evidence (e.g., document analysis, interviews with the HR department and key informants), which is characteristic of case study methodology in the field of social sciences. For the present research, we selected a NPO that is struggling with poverty and gets involved in HR issues. Located in a middle-sized city in the United Kingdom, this NPO works to reduce inequalities in underdeveloped areas. It employs 47 people based in the UK.

We conducted five semi-structured interviews with key actors of the NPO, among whom the head of the HR department, a manager, and several employees with high or low tenure. We also provide an in-depth analysis of the HR handbook which extensively describes the organization's HR policies. Finally, one of the authors undertook a seven-month mission within the organization and was able to carefully observe its HR practices. A table was drawn up from these different sources in order to identify the challenges relating to the implementation of HPWPs. Our results are detailed below.

\section{Results}

Staffing

The main challenge for the third sector is attracting and hiring qualified applicants. We introduce the three main dimensions of staffing: job description, advertisement, and assessment of skills.

First of all, the recruitment process targets to attract as much applicants as possible. Interviewees often qualify the standard job description as "quite general so it does attract the maximum of people" highlighting that, at the end, "all buzzwords people would recognize" are present. "Fast-paced", "dynamic" or "motivated self-starter" are frequently used expressions. Nevertheless, an interviewee notes that a recent job description mentions "nonfinancial benefits", which may be a particularity of the sector.

The HR handbook specifies that there must be various ways of advertising a job opportunity depending amongst other things on the position sought. It is stipulated that local and national press, recruitment agencies, relevant websites or informal advertising through partners may be used, with the goal of targeting the best applicants for each position while avoiding irrelevant ones. Advertisement is mainly carried out through the organization website and a national newspaper, which advertise Charity Jobs on certain days. These two ways of advertising are free. Recruitment agencies are not really used in that context. Recruitment agencies are "not used as much as [the charity] may want to, because of the need to justify costs to donors". Another interviewee qualified this choice as "making sense" since it allows low costs and is still quite efficient in terms of number of applications received: "I think the current strategy works quite well. They do get a lot of applications for not much cost."

As for the assessment of skills, all interviewed people considered this part of the recruitment process as "very important" or even "vital". As seen in the HR Handbook or in the life-experience within the organization, all applicants are asked to go through various tests, depending on the department they are applying to. For example, the applicants for the Finance department are doing a test with Excel. The importance of such a process is explained by an interviewee: "we potentially don't have as large team as we might like. So we need people to be operational as soon as possible. And therefore we need to recruit people with the correct skills." Another employee explained that she believed this process is "taken quite seriously, in fact sometimes even too seriously for the junior employees. For instance, just for internships, you go through two interviews and a writing test." Indeed, the skills tested are not always used or required for the job. But she admits it is "fair enough", as they want "to get the best qualified people." Nonetheless, another employee stated that the skills assessment is not used "as much as it should be" in the 
nonprofit sector. She also pointed out that psychometric test are also underused compared to the for-profit sector, because it is expensive to implement.

Lastly, the recruiting process is quite fast. As an interviewee noticed, it takes usually two and a half months. Another one explains that "recruitment is quite reactive and flexible, which is ad hoc because we are a small organization". However, it takes a lot of time and involvement for the staff. For each applicant's interview, there are two or three officers interviewing. Moreover, the process consists in conducting two interviews before the recruitment (sometimes there are even three interviews). As the turnover is quite high, and the need to hire new employees increases, the process takes a lot of time for the staff. An employee remarks that "the whole recruitment process is done within the team. More support from the HR team is going to be critical". There is thus the risk to not have the maximum implication of the staff in the recruitment process.

\section{Compensation}

In this part, we focused on the competitive pay level, the fringe benefits and the altruism payoff which can be considered as specificities of NPOs.

The pay level is considered as "reasonable", and people feel "adequately compensated". The HR handbook states that the organization pays relatively well comparing to other organization in the nonprofit sector. A salary benchmark is used as well for comparison with other NPOs. The studied organization is said to have "a competitive pay level within the nonprofit sector". Nevertheless, it was mentioned that when workload gets too high, "sometimes it might seem unfair. Yes, we are passionate about the cause but one thing about the nonprofit sector is kind of a guilt factor. A way bigger responsibility is on you. People lives can be affected." Regarding the sector, "it has improved a lot". If it is "less paid" than in the private sector, the pay cut you have to take is less important, and sometimes "compensated by the package." However, when considering the workload and extra hours, the job may be considered underpaid compared to the for-profit world.

Fringe benefits are considered as limited. There are less important than in the for-profit sector because "every bit of money should go to the cause". Another employee stated that "donors are getting to understand" such expenses. The studied organization is also recognized as the first to offer "an incentive scheme, so you receive a bonus". An employee states: "[fringe benefit] did impact my decision definitely". Other than that, it seems that the NPO offers "very similar" fringe benefits that are usually "statutory required" (pension scheme, leave days etc.)

Regarding the altruism payoff, things such as "I worked for a corporate company before and it didn't fulfill me really", "It would be hard to go back to for-profit now" or "I know I have an impact on lives" have been said by interviewees. It hence seems that going to the nonprofit sector is a choice. An employee highlights that "you have to be committed to the cause, specifically at a junior level". The impact of the job activities influence the perception of the job and its pay level: "This tangibility absolutely helps to accept my pay level. I feel better about myself."

\section{Training And Personal Development} offered.

We investigate how Training and Personal Development are advertised and under what form they are

Employees consider Training and Personal Development as important to "feel more confident in your job and the challenges it presents". They believe this topic is important for the sector, in order "to get the best skills from the limited staff you have". The needs for charity are specific, and an offer of charity-oriented training course exists.

The policy regarding Training and Personal Development is relatively new. As explained by the person in charge of Human Resources, "we have just launched our Benefits Policy [...] which details a learning and development policy and gives information on the access to a training budget for identified courses etc." An employee reckons: "I don't think it's given the importance it should be sometimes." 
Employees perceive the training possibility but the recurrent idea regarding this topic is "people need to be proactive". The HR Handbook explains that training needs should be identified by the employee and the line manager on a yearly basis during the annual appraisal. There is no explicit reference to an organizational strategy towards training. As one of our interviewees explains, "[Training] has to be driven by staff, which has to be proactive. But we don't have much time to think about it and look for conferences or training." Another one adds: "It has been mentioned more recently. We have budget for it. You just need to ask your management. Ideally, we would have a lot more of training and the budget is there; the willingness to let people do is there." A third employee also highlights that "asking for training is also not the most obvious thing to do."

An employee explains her experience: "During the appraisal process, you get a bonus. You can either stay with the bonus or the organization match the money again and it all goes to a training course. I would have liked to have more time to think about my options. But it happened in January, one of the busiest time of the year. I was still thinking about it when I realized it was too late." Generally speaking, training and personal development are not widely advertised, as confirmed by HR handbook and the work experience inside the organization. "It is very occasionally mentioned as a possibility but not advertised".

The general feeling is thus that if training is possible and efforts are made to encourage it, the workload is too heavy and the support in terms of what training to get is too weak to actually get it. In the studied organization, training is looked for and chosen by the employee, and has to be approved by the hierarchy. Interviewees that underwent training declare they had "no opposition" when they found the course. Besides, the Financial Team tries to support accounting qualification and, as the Person in charge of the Human Resources explains, "with growth comes a wide range of issues and to resolve this, my role has moved into an HR function, completing CIPD HR Qualifications last year, to ensure that we had someone in the office who was qualified."

Interviewees also mentioned that perceiving the real output they could get from training is hard. And because of the costs, some employees would rather not risk disappointment: "Do I want to risk money to go and maybe hear someone telling me what I've been doing for six months, when I have deadlines coming?"

\section{Flexibility Of Jobs Assignments}

We investigated the flexibility of job assignments among and across teams, as well as how relevant it is perceived by the sector as a whole. Nothing was developed in the HR handbook about those topics except that the training section highlights the possibility of lateral job changes, as well as work shadowing. We thus based our analysis on the interviews and confirmed what was said by our own observation of the functioning of the organization.

In a general manner, this issue of task flexibility within the nonprofit sector is qualified as "very relevant" by the staff. If they believe "it is useful in any job", they do agree that because of "limited resources", the organization needs a "fully functioning team if people are on leave". It is perceived as a key factor for "successful teams."

As for the studied organization, the person in charge of the Human Resources explains that "Task flexibility across teams can be limiting but we actively encourage teams to integrate with training and induction events for new joiners, integration amongst Senior Management Team members for example." Another employee tells us that "there used to be a project for having interns working in different teams along their internship." This could not happen due to "a time-pressure issue." All interviewed employees consider that there is limited flexibility of jobs assignments across teams. The idea that emerges from interviewees is that "teams are focused in what they do". Tasks are not perceived as flexible across teams. Their work eventually gets combined for reports, but tasks are too different for allowing flexibility.

Regarding flexibility within teams, the person in charge of human resources explains that "tasks are shared and in terms of covering if someone is out of the office, there are specific manuals in place which explains particular procedures to follow covering all aspects of the teams function." This statement is supported by all employees: "Within our team, we share the knowledge, because people leave. We need a proper handover" or "Within my team, 
we try to implement a knowledge and information management." Nevertheless, it is mentioned that people are usually "in charge of a country or donor", which limits the flexibility. This agrees with what another interviewee says, that "it is becoming a bit more rigid". This flexibility is also sometimes perceived as "not developed over time but rushed towards the deadline".

\section{Communication}

In this section, we present the results according to communication regarding operations, the communication regarding employees' feedback and participation and communication within teams. The HR handbook doesn't deal explicitly with these topics.

Communication about operations mainly occurs through job-related activities. Perceptions vary, from "quite good" to "could be better". There used to be a newsletter every month, "now it is once every two to six months". There is also little time to remain informed because of everyone's workload: "It could be more of a constant stream". Nevertheless, all agree that the communication is quite good regarding new grants. Senior management has a weekly meeting to disseminate information. Additionally, every year, there is a presentation of the Evidence of Investment. This document is accessible on the intranet as well. This kind of communication has a positive impact, though some mentioned to be "too busy to appreciate it". But "it helps to make you feel involved, part of the bigger picture, to work harder."

Regarding the opportunity to give feedback and participate in the organization's strategy, the corporate retreat day gives opportunity for staff to express what they want for the organization and their team in five years' time. That takes place "before [the new strategy] was worked on". Nevertheless, employees state that there is not as much communication "as [they] would like". It feels it is something they are waiting for and don't feel the executive team is touching base with them as much as they would like to. One reasons of this lack of communication is the increase in staff during previous years. Gossip is not effective anymore and the high workload delays the formalizing of important information communication.

The communication across teams is "not as good as it could be", and more specifically, "not as strong as it used to be since [the organization] is growing." An employee explained "it would be nicer if it was a constant stream, if everybody's knowledge was shared".

\section{DISCUSSION}

There is an extensive need for NPOs to become more effective. The economic crisis and its result - the increased competitiveness with other NPOs to obtain funds - force them to develop their human resources practices. We thus studied the challenges of implementing HPWPs in the nonprofit sector in order to achieve this goal.

First of all, NPOs should not hesitate to spend time and money for the implementation of HPWPs. Indeed, NPOs might be reluctant to do so. Public administration and donors are interested in organizations that give the higher percentage of funds to their activity. Then, deciding as part of the organization strategy to spend time and money to develop expensive human resources practices is not appealing to external stakeholders. This pressure is even increased in financial crisis time, when funds are getting scarce. However, the potential benefits resulting from HPWPs may make NPOs more competitive and may even reduce some costs.

Secondly, the implementation of these HPWPs should be adapted to the specificities of NPOs. NPOs struggle to find solutions as the sector growths and there is a greater demand for their services. Because it is seen as in between for-profit and public sectors, the first move has been to apply human resource management practices from those both sectors. Isomorphic behavior started to spread in the nonprofit sector with the reproduction of human resources practices, policies and programs from the for-profit and public sector (Beck et al., 2008). This started to make NPOs more business-like. The economic crisis has just emphasized such practice with a change of mind toward a market-oriented strategy. 
Accordingly, NPOs have started to professionalize their employees, hired trained managers, have invested in information systems, and worked with strategists and analysts (McCandless Baluch, 2012). Management costs have increased significantly as NPOs have grown and developed a more professional attitude towards their management (Hurrel et al., 2011). Nevertheless, these organizations have specificities that need to be taken into account when managing and dealing with human resources. The nonprofit sector needs to adapt tools from the forprofit sector and make their own model out of it. Few examples of such adaptation regarding the five tools described in this article are presented below.

Regarding staffing, one of the main topics of interest is skills testing. This is an effective and not-expensive way to check whether the applicant skills meet the organization's needs. Interpersonal skills are harder and more expensive to assess. Nevertheless, this can be replaced by assessing how the applicant values meet the organization's values. A specific emphasis on the organization's values and activities would allow the applicants to recognize the personal benefits they can gain from it. Most of this sector's employees are working there, looking for meaning in their work. Highlighting this meaning when advertising and selecting is the best way to attract highly motivated and committed employees. In order to attract candidates, an emphasis on the organization's missions and values has thus to be made when advertising and interviewing applicants.

Compensation must be considered in a different way in the nonprofit sector. Employees are not expecting a high pay level. And NPOs should perhaps not pay as high as in the for-profit sector. Indeed, it can represent a signal in order to attract people motivated by the values and missions of the organization. Besides, the personal aspect of the contract is more important than in the other sectors. Performance pay is difficult to implement. Hence, these HPWPs should focus on benchmarking the sector in order to offer a reasonable pay level. Apart from that, fringe benefits should be fostered. Flexible work environment, family-oriented policies etc. can compensate lower pay levels.

In order to develop their workforce skills and to improve the organization's efficiency, NPOs should invest in training. Training can be considered as a fringe benefit. It would also foster the employee's commitment to the organization and then tackle the turnover issue of the sector. This is an investment that needs to be done. For that purpose the Human Resources Department has to embrace it and communicate actively about it. The change in mentality will then start, and overheads costs in training and development will then be easier to actually implement.

Given the high workload, job flexibility may be hard to implement in NPOs. Job rotation among teams might be too hard to carry out in first place. It seems better to concentrate the effort on job rotation inside the team. Indeed developing multiskilling can weaken the boredom of doing the same task, especially for people not working for money.

Finally, internal communication must be a priority for NPOs. One of the raison d'être of NPOs is the voice given to the employees for providing their opinion about the missions and strategy of the organization. This voice leads to the commitment of the employees. In order to do that, employees need all the information about the organization. NPOs must stop relying exclusively on informal communication. Despite the high workload, regular meetings, newsletter, direct communication by the manager must be mandatory inside those organizations.

\section{CONCLUSION}

The impact of the last economic crisis has created challenges for the nonprofit sector. It highlighted the need of professionalization that this sector is now facing. Nonprofit sector and organizations have usually been created on foundations that differ from the for-profit sector, by defending causes and values. The entire philosophy behind such organizations differs thus radically from the for-profit sector. The way human resources are managed may differ as well.

We have selected some of these practices and consider how they can be implemented and relevant for the challenges the nonprofit sector is currently facing. Human resource management can be adapted to this specific context while benefiting those organiztions. 


\section{AUTHOR INFORMATION}

Alice Robineau graduated from Kedge Business School (France). Her main topic of interest is human resources management in nonprofit organizations. Alice Robineau, Kedge Business School, 680 avenue de la Libération, 33405 Talence cedex, France.

Marc Ohana is professor of organizational behavior at Kedge Business School (France). His research mainly deals with the consequences of organizational justice on motivation in nonprofit organizations. Marc Ohana, Kedge Business School, 680 avenue de la Libération, 33405 Talence cedex, France. Email: marc.ohana@kedgebs.com

Sophie Swaton is a post-doc research assistant with the University of Lausanne, Switzerland. Her research focuses on social economy and social entrepreneurship. Sophie Swaton, Centre Walras-Pareto, Université de Lausanne, Unicentre - CH-1015 Lausanne - Switzerland

\section{REFERENCES}

1. Akingbola, K. (2006). Strategic choices and changes in Non-Profit Organizations. Strategic Change, 15(6), 265-281.

2. Ashton, D. N., \& Sung, J. (2002). Supporting workplace learning for high performance working. International Labour Organization.

3. Backman, E.V., Grossman, A. \& Rangan, V.K. (2000). Introduction. Nonprofit and Voluntary Sector Quarterly, 29, 2-8.

4. Bartel, A. P. (2000). Measuring the Employer's Return on Investments in Training: Evidence from the Literature. Industrial Relations: A Journal of Economy and Society, 39, 502-524.

5. Beck, T. E., Lengnick-Hall, C. A., \& Lengnick-Hall, M. L. (2008). Solutions out of context: Examining the transfer of business concepts to nonprofit organizations. Nonprofit Management and Leadership, 19(2), 153-171.

6. Becker, B. E., Huselid, M. A. (1998). High performance work systems and firm performance: A synthesis of research and managerial implications. Research in personnel and human resource management, 53-102.

7. Ben-Ner, A., Ren, T., \& Paulson, D. F. (2011). A Sectoral Comparison of Wage Levels and Wage Inequality in Human Services Industries. Nonprofit and Voluntary Sector Quarterly, 40(4), 608-633.

8. Berg, P. (1999). The effects of high performance work practices on job satisfaction in the United States steel industry. Relations industrielles/Industrial relations, 54(1), 111-135.

9. Blanchard, P. \& Thacker, J. (1998). Effective Training: Systems, Strategies and Practices. Prentice Hall, New Jersey.

10. Brandl, J. \& Güttel, W.H. (2007). Organizational antecedents of pay-for-performance systems in Nonprofit Organizations. Voluntas, 18(2), 176-199.

11. De Cooman, R., De Gieter, S., Pepermans, R., \& Jegers, M. (2011). A Cross-Sector Comparison of Motivation-Related Concepts in For-Profit and Not-For-Profit Service Organizations. Nonprofit and Voluntary Sector Quarterly, 40(2), 296-317.

12. De Prins, P. \& Henderickxe, E. (2007). HRM effectiveness in Older's People and Nursing Homes: the Search for Best (Quality) Practices. Nonprofit and Voluntary Sector Quarterly, 36(4), 549-57.

13. Dolan, D.A. (2002). Training Needs of Administrators in the Nonprofit Sector. Nonprofit Management \& Leadership, 12(3), 277-292.

14. Evans, W. R., \& Davis, W. D. (2005). High-performance work systems and organizational performance: The mediating role of internal social structure. Journal of Management, 31(5), 758-775.

15. Haley-Lock, A. \& Kruzich, J. (2008). Serving Workers in the Human Services: The Roles of Organizational Ownership, Chain Affiliation and Professional Leadership in Frontline job benefits. Nonprofit and Voluntary Sector Quarterly, 37(3), 443-467.

16. Handy, F. \& Katz, E. (1998). The wage differential between Nonprofit Institutions and corporations: Getting more by paying less?. Journal of Comparative Economics, 26(2), 246-261.

17. Hurrel, S.A., Warhurst, C. \& Nickson D. (2012). Giving Miss Marple a Makeover: Graduate Recruitment, Systems Failure, and the Scottish Voluntary Sector. Nonprofit and Voluntary Sector Quarterly, 10(2), 336355. 
18. Kearns, K.P., Bell, D., Deem, B., \& McShane, L. (2014). How Nonprofit Leaders Evaluate Funding Sources: An Exploratory Study of Nonprofit Leaders. Nonprofit and Voluntary Sector Quarterly, 43(1), 121-143.

19. McCandless Baluch, A. (2012). Human resources management in non-profit organisations. New York, Routledge.

20. Ohana, M., \& Meyer, M. (2010). Should I stay or should I go now? Investigating the intention to quit of the permanent staff in social enterprises. European Management Journal, 28(6), 441-454.

21. Ohana, M., Meyer, M., \& Swaton, S. (2013). Decision-Making in Social Enterprises: Exploring the Link Between Employee Participation and Organizational Commitment. Nonprofit and Voluntary Sector Quarterly, 42(6), 1092-1110.

22. Parry, E., Kelliher, C., Mills, T. \& Tyson S. (2005). Comparing HRM in the Voluntary and Public Sectors. Personnel Review, 34(5), 588-602.

23. Posthuma, R.A., Campion, M.C., Masimova, M., \& Campion, M.A. (forthcoming). A high performance work practices taxonomy integrating the literature and directing future research. Journal of Management.

24. Ridder, H. G., \& McCandless, A. (2010). Influences on the Architecture of Human Resource Management in Nonprofit Organizations An Analytical Framework. Nonprofit and Voluntary Sector Quarterly, 39(1), 124-141.

25. Subramony, M. (2009). A meta-analytic investigation of the relationship between HRM bundles and firm performance. Human resource management, 48(5), 745-768.

26. Sun, L.Y., Aryee, S., Law, K.S. (2007). High-Performance Human Resource Practices, Citizenship Behavior, and Organizational Performance: A Relational Perspective. Academy of Management Journal, 50(3), 558-577.

27. Tamkin P (2004). High Performance Work Practices. HR Network Paper MP36, Institute for Employment Studies.

28. Takeuchi, R., Lepak, D.P., Wang, H., \& Takeuchi, K. (2007). An empirical examination of the mechanisms mediating between high-performance work systems and the performance of Japanese organizations. Journal of Applied Psychology, 92(4), 1069-1083.

29. Watson, M. R., \& Abzug, R. (2005). Finding the ones you want, keeping the ones you find. The JosseyBass handbook of nonprofit leadership \& management, 623-660.

30. Way, S.A. (2002). High Performance Work Systems and intermediate indicators of firm performance within the US Small business sector. Journal of Management, 28(6), 765-785.

31. Way, S.A. \& Thacker, J.W. (2001). The successful implementation of strategic human resource management practices: A Canadian survey. International Journal of Management, 18(1), 25-32.

32. Wright, P.M., Snell, S.A. (1998). Toward a Unifying Framework for Exploring Fit and Flexibility in Strategic Human Resource Management. Academy of Management Review, 23(4), 756-772.

33. Yin, R. (1993). Applications of case study research. Newbury Park, CA: Sage Publishing. 
NOTES 